\title{
KAJIAN PENGARUH TEKNIK PEMBUATAN LUBANG TERHADAP KEKUATAN TARIK KOMPOSIT HIBRID SERAT GELAS DAN SERAT KARUNG PLASTIK
}

\author{
Kuncoro Diharjo \\ Jurusan Teknik Mesin Fakultas Teknik \\ Universitas Negeri Sebelas Maret Surakarta \\ Email: kuncorodiharjo@uns.ac.id
}

\begin{abstract}
In panels or components, there are holes for joinning with other part. There are two method for manufacturing a hole, i.e. by boring and molding processes. The objective of this research is to investigate the effect of hole manufacturing method on the tensile properties of hybride composite reinforced chopped strand mat of E-glass fiber and woven roving fiber of plastic bag.

The materials in this research are plastic bag fiber, chopped strand mat of E-glass fiber (300 gr/m²), unsaturated polyester 157 BQTN-EX, and MEKPO hardener. The composite was made using press mold method, prepared with 4 laminates of glass fiber and 3 laminates of plastic bag fiber. The weight fraction fiber $\left(W_{f}\right)$ of the composite was around $38 \%$. The tensile test specimens were produced according to ASTM D 5766. In the middle of each specimen, there is a hole with 4,6, or $8 \mathrm{~mm}$ in diameter. There are two types hole, i.e. holes were manufactured using boring and molding process methods.

The result shows that the highest tensile strength of the composites occurs on the composite with $6 \mathrm{~mm}$ in diameter of hole manufactured by boring and molding process. It can be recommended that composite has the higher strength for $6 \mathrm{~mm}$ in diameter of hole for joining. The composites with 4 and 6 diameters of holes manufactured by molding process have higher tensile strength compared to that manufactured by boring process. In contrast, the tensile strength of the composite with $8 \mathrm{~mm}$ in diameter of hole produced by boring is higher than that of the composite with $8 \mathrm{~mm}$ in diameter of hole produced by molding process.

Keywords : plastic bag fiber, E-glass fiber, molding process, boring.
\end{abstract}

\section{PENDAHULUAN}

Penggunaan material yang siap diaplikasikan sebagai komponen pada suatu struktur menuntut adanya peningkatan sifat mekanis yang tinggi. Para rekayasawan pun selalu melakukan berbagai kajian riset untuk merekayasa material baru yang memiliki sifat fisis-mekanis lebih baik, seperti bahan baru komposit. Komposit berpenguat serat merupakan jenis komposit yang paling banyak dikembangkan [6].

Hampir semua komponen, baik logam maupun non logam, mengalami proses penyambungan (joining) dengan komponen lain. Komponen logam dapat disambung dengan las, dibaut, dan dikeling. Namun khusus bahan non metal seperti komposit, penyambungannya tidak dapat dilakukan dengan pengelasan. Salah satu jenis sambungan yang cocok untuk bahan komposit adalah sambungan 
baut dan keling [11]. Penyambungan ini memerlukan lubang sebagai tempat dudukan baut atau keling. Daerah sekitar lubang merupakan daerah kritis terhadap awal terjadinya kegagalan. Teknik pembuatan lubang dan variasi diameter lubang sangat menentukan kekuatan kekuatannya, khususnya di daerah sekitar lubang. Teknik pembuatan lubang pada komposit dapat dilakukan dengan dua cara, yaitu pembuatan lubang dengan cara dicetak dan dibor. Teknik penguatan daerah sekitar lubang dapat dilakukan dengan dua cara yaitu meminimalkan daerah yang miskin penguat (serat) dan meminimalkan kemungkinan terjadinya delaminasi.

Salah satu jenis serat komersial yang sudah digunakan sebagai penguat komposit adalah serat gelas. Serat ini memiliki kekuatan dan ketahanan terhadap lingungan yang tinggi. Di sisi lain, teknologi rekayasa bahan komposit juga dapat dikembangkan dengan memanfaatkan berbagai jenis bahan serat yang murah dan kuat, seperti serat limbah karung plastik. Karung plastik merupakan kategori bahan non-organik yang banyak dipakai sebagai bahan pengemas, seperti sebagai karung beras, pupuk, dan makanan ternak. Kebanyakan karung plastik yang sudah tak dipakai hanya digunakan untuk kepentingan yang kurang bermanfaat atau bahkan hanya dibuang menjadi limbah yang mencemari tanah. Padahal bahan ini mempunyai kekuatan yang cukup tinggi sehingga dapat digunakan sebagai penguat bahan komposit.

Salah satu kelemahan pemanfaatan serat karung plastik sebagai penguat komposit adalah memiliki ikatan dengan resin yang kurang baik, sehingga mudah mengalami delaminasi. Hal ini dapat diatasi dengan mengkombinasikan penguatan serat karung plastik dan serat gelas. Berdasarkan uraian di atas, kajian teknik pembuatan lubang terhadap kekuatan tarik bahan komposit hibrid serat karung plastik dan serat gelas dipandang penting untuk diteliti. Hasil penelitian ini akan memberikan rekomendasi teknik pembuatan lubang yang paling baik untuk diterapkan di industri.

\section{TUJUAN PENELITIAN}

Tujuan penelitian ini adalah menyelidiki pengaruh teknik pembuatan lubang dengan variasi diameter yang berbeda terhadap optimasi kekuatan bahan komposit hibrid yang diperkuat kombinasi serat karung plastik dan serat E-glass acak. Analisis kegagalan akan dilakukan dengan menganalisis tingkat delaminasi di sekitar lubang.

\section{TINJAUAN PUSTAKA}

Retak awal akan muncul di daerah yang paling lemah, seperti di daerah sekitar lubang. Penghambatan perambatan retak ini dapat dilakukan dengan cara menumpulkan ujung retak, seperti dibor. Ujung retak yang runcing akan mempercepat perluasan daerah plastis, sehingga pada tahapan pembebanan berikutnya akan terjadinya penjalaran retak [4].

Butiran liat material di daerah ujung retak merupakan penghambat perambatan retak, karena daerah ini merupakan daerah yang elastis. Namun, butiran yang keras dan getas diujung retak merupakan pemicu penjalaran retak 
[5]. Proses pembuatan lubang dengan cara dibor pada bahan komposit glass fiber reinforced plasstic (GFRP) akan menyebabkan keretakan dan delaminasi disekitar lubang. Adanya delaminasi dan retak di daerah sekitar lubang ini akan memperlemah kekuatan komposit GFRP tersebut. Akibatnya, beban yang dapat diterima menjadi lebih rendah dan umur pakainya pun menjadi lebih pendek.

a. Serat Karung Plastik

Karung plastik dibuat dari polimer polypropilen (PP) yang bersifat termoplastik (Pertamina UPPDN VI). Bahan baku polipropilen didapat dengan menguraikan petroleum (naftan). Polypropilen ini dibentuk oleh $\mathrm{n}$ satuan monomer propilen. Molekul rantai polypropilen akan memberikan sifat termoplastik seiring dengan kenaikan temperatur, serta dapat mencair dan mengalir. Massa jenis PP rendah yaitu sekitar $0.9007 \mathrm{gr} / \mathrm{cm}^{3}$ (ASTM D 792) [1]. PP termasuk golongan polimer yang paling ringan dan dapat terbakar kalau dinyalakan. Titik leleh PP adalah sekitar $176^{\circ} \mathrm{C}$ [13].<smiles>CC=CC(C)C</smiles>

Gambar 1. Skema ikatan kimia dari polypropilen.

b. Serat Gelas (glass fiber)

Serat gelas dibuat dari campuran kaolin, sand, colemantie, limestone yang dilebur dalam furnace electrically heated bushing. Selanjutnya, cairan material tersebut ditarik dalam bentuk filamen (serat) dengan diameter 5-24 mm dan ditaburkan di atas belt conveyor dengan orientasi acak. Serat acak tersebut diikat oleh pengikat organik polyvinil acetate untuk menghasilkan ikatan longgar mat terbuka yang untuk dilakukan laminasi. Tipe serat gelas yang paling banyak digunakan di industri adalah E-glass baik berbentuk random chopped strand mat (CSM) maupun woven roving [2], [8].

c. $\quad$ Resin Unsaturated Polyester (UP)

Unsaturated Polyester (UP) merupakan jenis resin thermoset. Resin UP memiliki sifat encer dan fluiditasnya baik sehingga dapat diaplikasikan mulai dari proses hand lay up yang sederhana sampai dengan proses yang kompleks. Banyaknya penggunaan resin ini didasarkan pada pertimbangan harga relatif murah, curing cepat, warna jernih, dan mudah penanganannya. (Billmeyer,1984). Katalis yang sering digunakan sebagai media untuk mempercepat pengerasan cairan resin (curing) adalah hardener metyl etyl keton peroksida (MEKPO). Kadar penggunaan hardener MEKPO adalah 1\% pada suhu kamar [3], [9]. 
d. Sambungan komposit

Sambungan pada komposit pada dasarnya ada 2 macam yaitu sambungan mekanik dan sambungan ikat (bonded joint). Sambungan mekanik dibuat dengan membuat lubang sebagai tempat dudukan baut atau keling sedangkan bonded joint dibuat dengan memberikan zat adesif antar lapisan yang akan disambung. Zat adhesif yang digunakan ini dinamakan adherens [10].

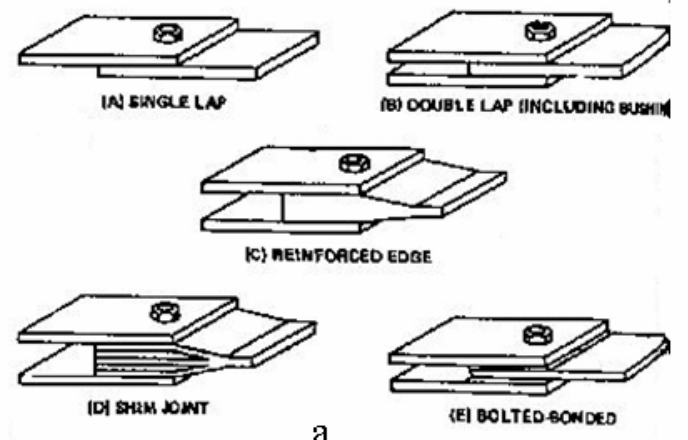

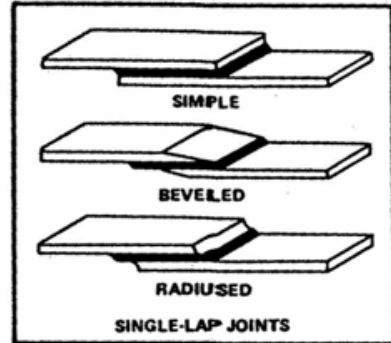

$b$

Gambar 2. Tipe-tipe dari (a) sambungan mekanik dan

(b) sambungan ikat (bonded joint)

Keuntungan penggunaan sambungan mekanik antara lain (1) replacement mudah bila terjadi kerusakan, (2) perlakuan permukaan sedikit, (3) mudah melakukan inspeksi kualitas sambungan. Namun demikian, sambungan ini juga memiliki kelemahan, yaitu (1) sambungan mekanik menimbulkan konsentrasi tegangan di daerah sekitar lubang dan (2) pembuatan lubang akan menimbulkan kerusakan serat. Kerusakan serat tersebut dapat berupa terjadinya misoriented fiber pada lubang yang dicetak dan terputusnya serat pada saat pembuatan lubang dengan cara dibor. Kekuatan sambungan mekanik sangat dipengaruhi oleh 3 faktor utama, yaitu:

a. Faktor geometri spesimen, seperti W/D dan $\mathrm{D} / \mathrm{t}$

b. Faktor material spesimen seperti orientasi serat dan susunan lamina yang digunakan

c. Cara pembuatan lubang

d. Kerusakan pada sambungan mekanik ditunjukkan pada gambar 4 .

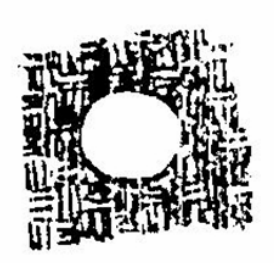

lubarlg stibor

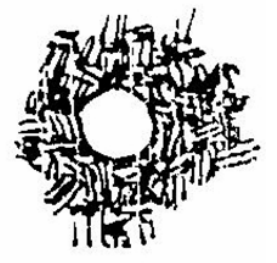

Luthang dicetal:

Gambar 3. Orientasi serat pada daerah lubang yang dibor dan dicetak. 


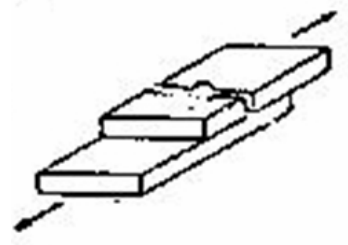

a. net tension

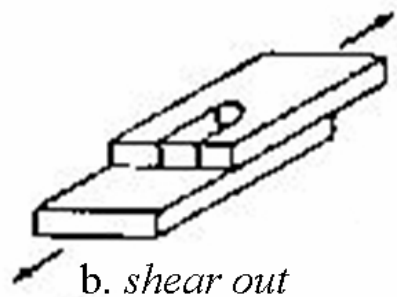

b. shear out

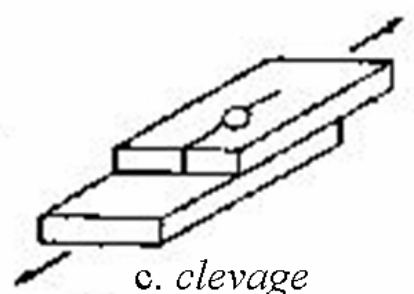

c. clevage

Gambar 4. Beberapa jenis kerusakan yang mungkin terjadi pada sambungan mekanik

Rasio antara besarnya diameter lubang dengan tebal spesimen berpengaruh terhadap besarnya geseran yang terjadi dan besarnya konsentrasi tegangan yang dihasilkan. Tetapi sampai sekarang, pada material komposit belum ada persamaan tertentu yang menjelaskan hubungan antara $\mathrm{D} / \mathrm{t}$ dengan besarnya konsentrasi tegangan yang dihasilkan. Besarnya konsentrasi tegangan dapat ditentukan dengan cara eksperimental menggunakan strain gage [10].

\section{METODE PENELITIAN}

Bahan utama penelitian ini adalah limbah karung plastik, serat E-glass, unsaturated polyester 157 BQTN-EX, dan hardener MEKPO. Pembuatan komposit dilakukan menggunakan metode press mold dengan fraksi massa serat sekitar $38 \%$. Komposit tersebut terseueun dari 7 lamina serat, yaitu 4 lamina serat gelas dan 3 lamina serat limbah karung plastik yang disusun secara berselang-seling. Spesimen uji dibuat dengan tarik komposit berlubang dibuat dengan mengacu pada standar ASTM D 5766, seperti pada gambar 5. Pembuatan lubang dilakukan dengan dua cara, yaitu dengan dibor dan dicetak langsung. Pengeboran lubang dilakukan dengan pisau bor HSS pada putaran $2055 \mathrm{rpm}$ dengan feed rate rata-rata sebesar $13 \mathrm{~mm} / \mathrm{s}$. Lubang tersebut divariasi diameternya $(4,6$, dan $8 \mathrm{~mm})$. Pengujian densitas dan kekuatan tarik serat dilakukan standar ASTM D 792 dan 3379.

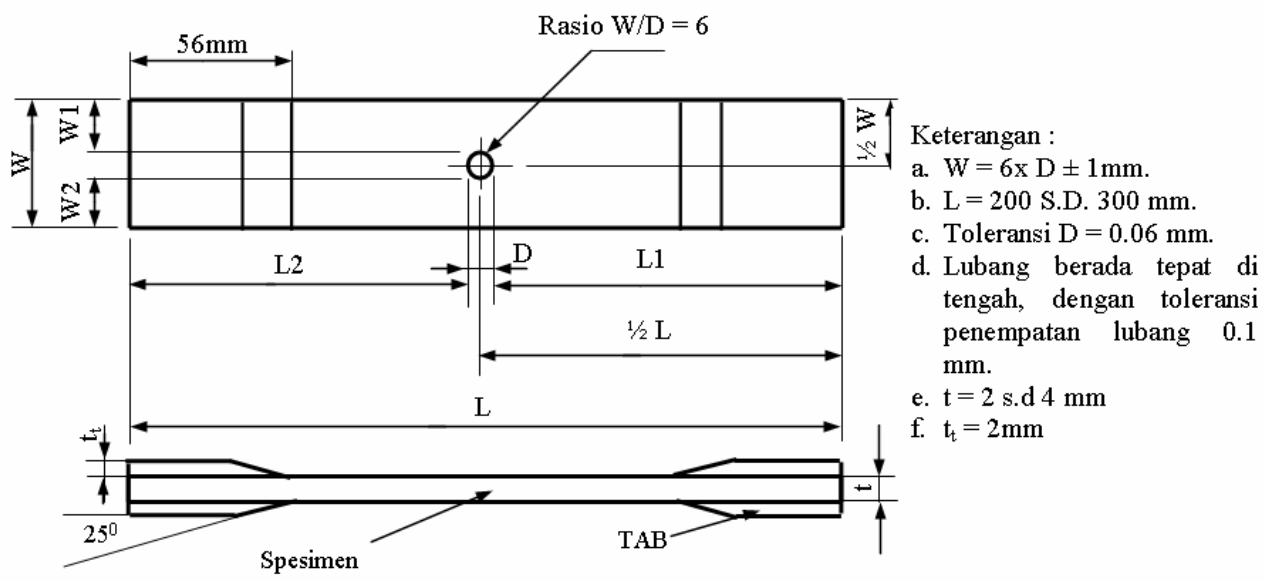

Gambar 5. Spesimen uji tarik komposit (ASTM D 5766) 
Kekuatan tarik komposit dapat dihitung dengan persamaan [7]:

$$
\sigma=F^{\max } / A
$$

Dengan catatan: $\sigma=$ kekuatan tarik maximum dari komposit berlubang, Fmax = beban maximum, dan $\mathrm{A}=$ luas penampang komposit dengan mengabaikan adanya lubang.

Pengamatan permukaan patah komposit setelah uji tarik dilakukan dengan menggunakan kamera digital. Berdasarkan analisis pada gambar 6, maka lebar delaminasi dapat dihitung dengan persamaan:

Lebar delaminasi : $l=\frac{l 1+l 2+l 3+l 4}{4}$

Jarak rata-rata dari tepi lubang ke tepi spesimen: $W 3=\frac{W 1+W 2}{2}$ 7 [12].

Prosedur pembuatan lubang dengan pengeboran ditunjukkan pada gambar

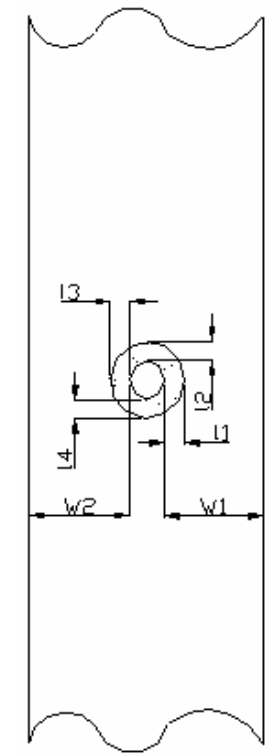

Gambar 6. Skema daerah yang terdeliminasi

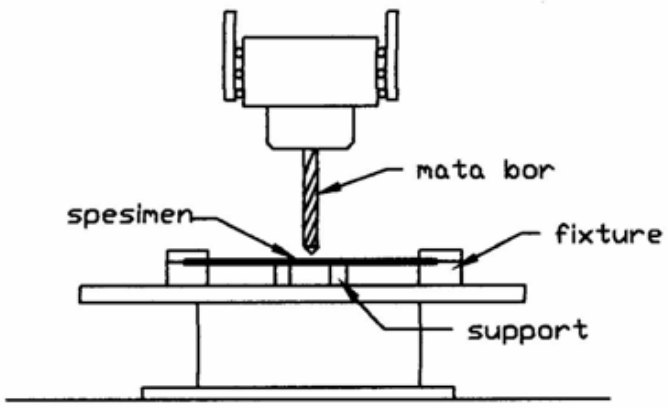

Gambar 7. Proses pembuatan lubang dibor

\section{HASIL DAN PEMBAHASAN}

Densitas dari serat E-glass menurut technical data fiber adalah sebesar 2,56 $\mathrm{gr} / \mathrm{cm}^{3}$ (Taiwan Glass Ind. Corp.), sedangkan hasil pengukuran densitas serat karung plastik adalah $0,899 \mathrm{gr} / \mathrm{cm}^{3}$. Dari data ini menunjukkan bahwa serat gelas memiliki struktur yang lebih padat dan unsur pembentuk yang lebih berat, seperi $\mathrm{SiO}_{2}$. Hasil pengukuran kekuatan tarik uk serat karung plastik tunggal adalah 493,68 MPa, sedangkan kekuatan tarik serat tunggal E-glass berdasar technical data adalah $3.430 \mathrm{MPa}$. Hal ini menunjukkan bahwa serat E-glass lebih kuat dibandingkan serat karung plastik. 
Pengujian densitas komposit yang dilakukan pada 45 sampel diperoleh harga densitas rata-rata sebesar $1.367 \mathrm{gr} / \mathrm{cm}^{3}$. Pengujian fraksi massa serat $\left(\mathrm{W}_{\mathrm{f}}\right)$ yang dilakukan per spesimen diperoleh $\left(\mathrm{W}_{\mathrm{f}}\right)$ rata-rata sebesar $38 \%$.

\subsection{Kekuatan Tarik Komposit}

Kehadiran lubang ditengan spesimen menurunkan kekuatan tarik komposit, karena menyebabkan efek takik atau sebagai konsentrator tegangan. Pada komposit dengan lubang berdiameter 4 dan $6 \mathrm{~mm}$, pembuatan lubang dengan cara dicetak lebih baik daripada dibor. Hal ini disebabkan oleh tidak adanya kerusakan delaminasi seperti yang terjadi pada saat pembuatan lubang dibor dan pada daerah sekitar lubang dicetak tidak terjadi daerah miskin serat (rich matrix). Namun, komposit dengan diameter lubang $8 \mathrm{~mm}$ yang dibor memiliki kekuatan tarik yang lebih tinggi. Efek kenaikan diameter pahat lebih kecil daripada peningkatan delaminasi sehingga membuat nilai $1 / \mathrm{W}_{3}$ turun, Besarnya rata-rata lebar delaminasi dan nilai dari $1 / \mathrm{W}_{3}$ seperti terlihat pada tabel 1. Grafik penurunan kekuatan tarik komposit dapat dilihat pada gambar 8 dan gambar 9 . Kerusakan selama proses pembuatan pada lubang dibor yaitu adanya kerusakan delaminasi, seperti terlihat pada gambar 10.

Tabel 1. Nilai rata-rata dari 1/W3

\begin{tabular}{|c|c|c|c|}
\hline No & Diameter Lubang Dibor $(\mathrm{mm})$ & rata-rata $1(\mathrm{~mm})$ & $1 / \mathrm{W}_{3}$ \\
\hline 1 & 4 & 2.76 & 0.34 \\
\hline 2 & 6 & 2.94 & 0.25 \\
\hline 3 & 8 & 3.25 & 0.20 \\
\hline
\end{tabular}
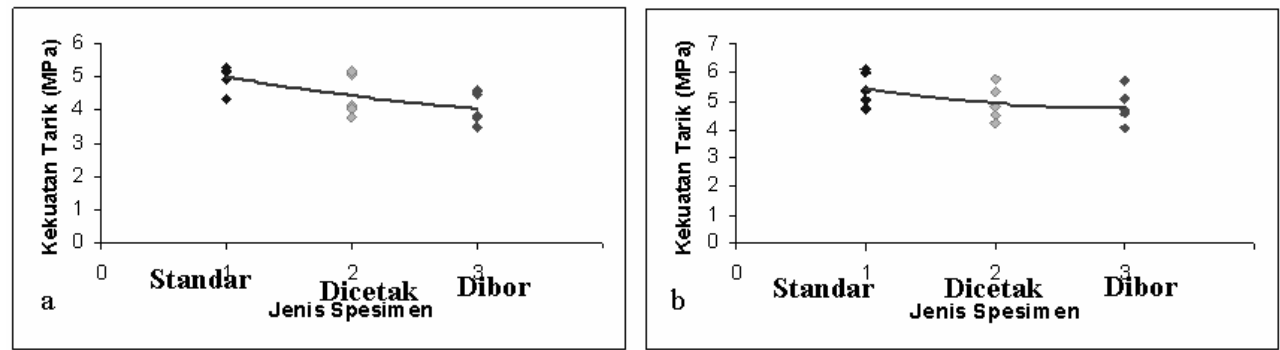

Gambar 8. Penurunan kekuatan tarik komposit dengan diameter lubang

(a) $4 \mathrm{~mm}$ dan (b) $6 \mathrm{~mm}$. 


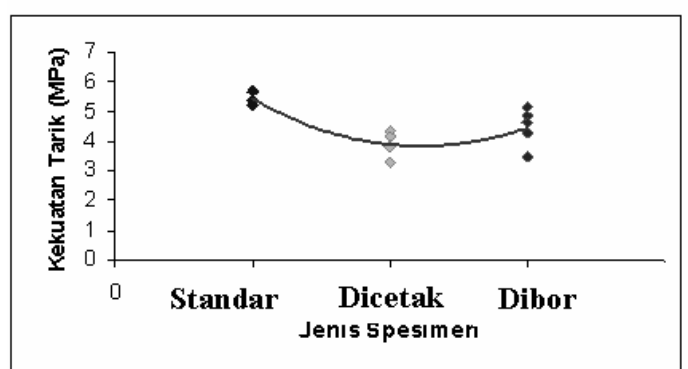

Gambar 9. Penurunan kekuatan tarik komposit dengan diameter lubang $8 \mathrm{~mm}$

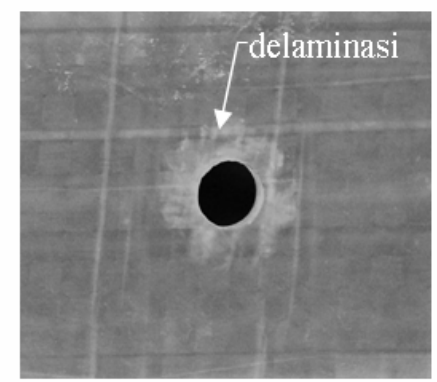

Gambar 10. Kerusakan di sekitar lubang dibor

Faktor geometri $(\mathrm{D} / \mathrm{t})$ sangat berpengaruh terhadap kekuatan tarik komposit berlubang. Pada harga $\mathrm{D} / \mathrm{t}$ yang optimal, harga konsentrasi tegangannya kecil sehingga kekuatan tariknya tinggi. Pada komposit ini, harga $\mathrm{D} / \mathrm{t}$ yang optimal terdapat pada komposit dengan lubang $6 \mathrm{~mm}$ dengan harga $\mathrm{D} / \mathrm{t}$ adalah 1,46 untuk lubang dibor dan 1,34 untuk lubang dicetak, seperti pada tabel 2. Pengaruh besarnya diameter lubang dibor dan dicetak terhadap besarnya kekuatan tarik ditunjukkan pada gambar 14 .

Tabel 2. Nilai rata-rata dari $\mathrm{D} / \mathrm{t}$

\begin{tabular}{|c|c|c|c|c|}
\hline \multirow{2}{*}{ No } & \multirow{2}{*}{ Jenis Lubang } & \multicolumn{3}{|c|}{$\begin{array}{c}\text { Diameter Lubang } \\
\text { (mm) }\end{array}$} \\
\cline { 3 - 5 } & & 4 & 6 & 8 \\
\hline 1 & Dibor & 0.97 & 1.46 & 1.92 \\
\hline 2 & Dicetak & 1.02 & 1.34 & 1.81 \\
\hline
\end{tabular}

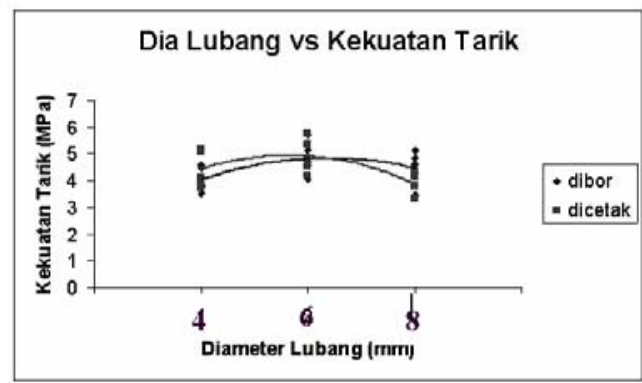

Gambar 11. Pengaruh diameter lubang dibor dan dicetak terhadap kekuatan tarik komposit

\subsection{Pengamatan Permukaan Patah Uji Tarik}

Kegagalan uji tarik komposit hibrid kombinasi serat gelas dan serat karung plastik berlubang adalah adanya kerusakan retakan dan delaminasi yang terkonsentrasi di sekitar lubang. Delaminasi ini dapat disebabkan karena ikatan antar muka resin unsaturated polyester dengan serat karung plastik yang kurang baik, seperti ditunjukkan pada gambar 12 dan gambar 13 . 

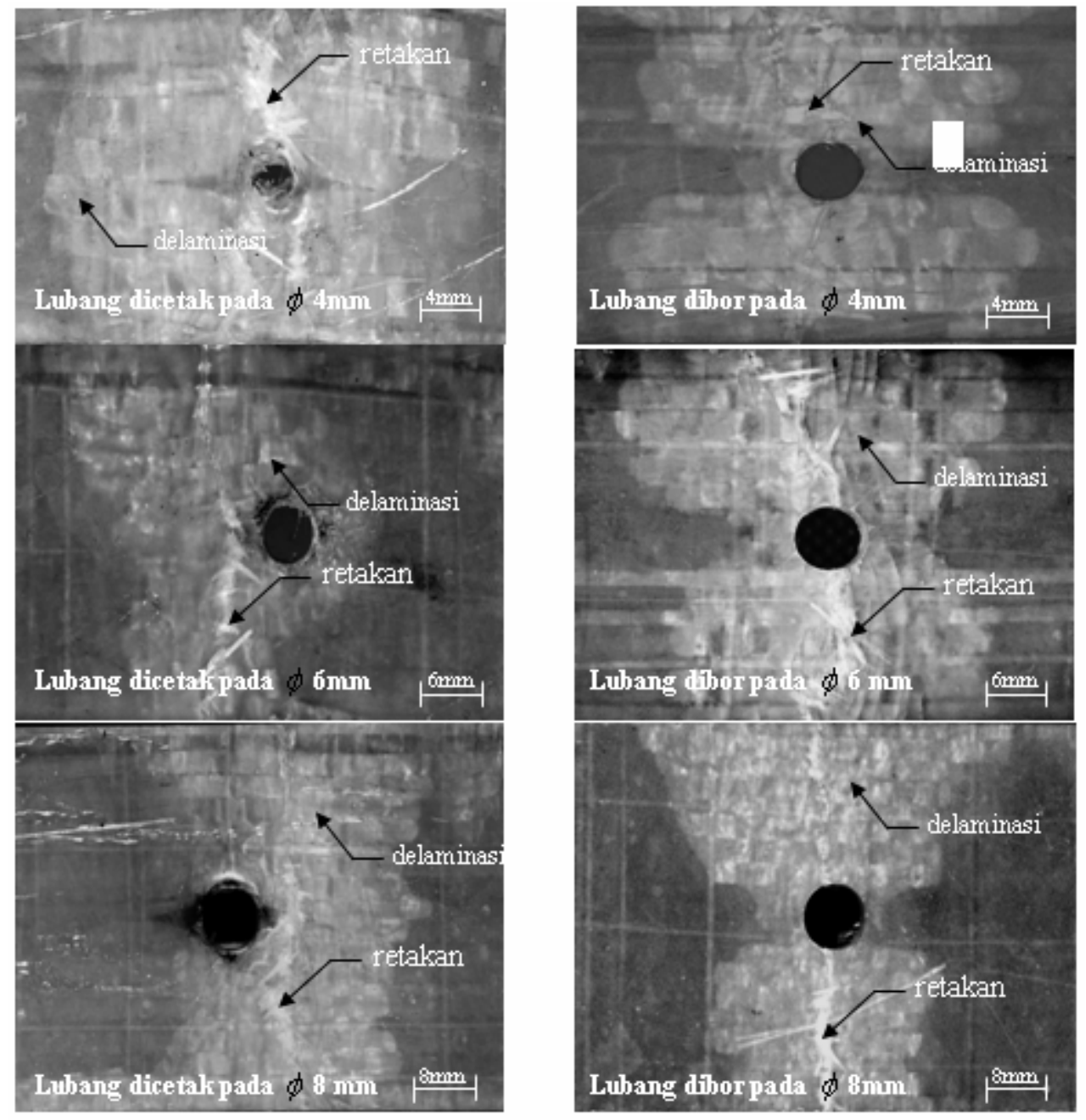

Gambar 12. Kegagalan hasil uji tarik komposit berlubang.

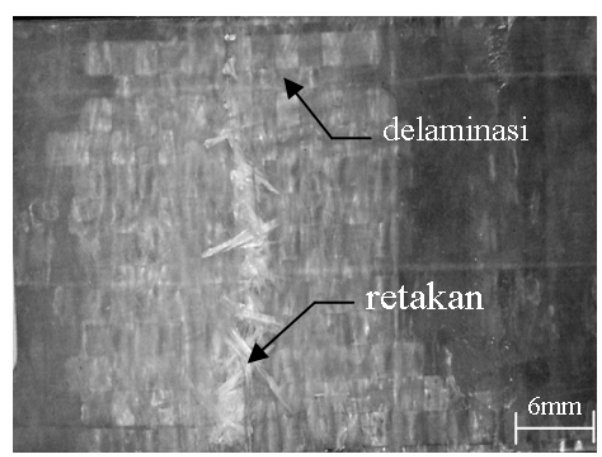

Gambar 13. Kegagalan hasil uji tarik komposit tidak berlubang (standar).

TEKNOIN, Vol. 11, No.1, Maret 2006, 55-64 


\section{SIMPULAN}

Berdasarkan analisa pembahasan hasil penelititan di atas maka dapat disimpulkan sebagai berikut:

a. Komposit dengan lubang $6 \mathrm{~mm}$ memiliki kekuatan tertinggi baik untuk lubang yang dicetak maupun yang dibor.

b. Komposit dengan diameter lubang 4 dan $6 \mathrm{~mm}$ yang dibuat dengan dicetak memiliki kekuatan tarik yang lebih tinggi dibandingkan dengan yang dibor. Namun sebaliknya, komposit dengan lubang $8 \mathrm{~mm}$ yang dibor memiliki kekuatan yang lebih tinggi.

c. Kegagalan komposit yang berlubang menunjukkan pola kegagalan delaminasi. Semakin besar delaminasinya kekuatannya pun semakin rendah.

\section{UCAPAN TERIMA KASIH}

Kami mengucapkan terima kasih kepada DP3M DIKTI yang telah mendanai penelitian ini melalui Progam Penelitian Dosen Muda. Ucapan terima kasih yang tulus juga kami sampaikan kepada Joko Wisnu Widodo, S.T. dan Staf Laboratorium Bahan Jurusan Teknik Mesin \& Industri UGM..

\section{PUSTAKA}

[1] Anonim. (1998) Annual Book ASTM Standart, USA

[2] Anonim. (2002) E, $R$ and D Glass Properties, Saint-Gobain Vetrotex, Germany

[3] Billmeyer F. (1984) Text Book Of Polymer Science, John Wiley \& Sons, New York

[4] Diharjo K. (1996) Karakteristik Laju Perambatan Retak pada Plat Alumunium 6061 T6, Skripsi, Teknik Mesin FT UGM, Yogyakarta

[5] Diharjo K. (2000) Karakteristik LelahPoros Baja S45C Bertakik V Akibat Kombinasi Beban Amplitudo Konstan dan Beban Tiba-tiba, Media TeknikTerakreditasi, No. 1 Th. XXIII, Edisi Pebruari 2001, ISSN 0216-3012, Fak. Teknik UGM, Yogyakarta

[6] Diharjo K. \& Triyono T. (2000) Material Teknik, Buku Pegangan Kuliah, UNS Press, Surakarta

[7] Gibson, O. F. (1994) Principle of Composite Materials Mechanics, McGraw-Hill Inc., NewYork, USA

[8] Ismoyo I. (1999) Dokumen Riset INKA-Rosella Baru, Litbang PTPN XI PK Rosella Baru, Surabaya

[9] Justus Kimia Raya. (2001) Technical Data Sheet, Jakarta.

[10] Mallick,P.K. (1988) Fiber-Reinforced Composite, Marcel Dekker Inc., New York, USA

[11] Schwartz M. (1984) Composite Materials Handbook, McGraw-Hill Inc.,NewYork, USA

[12] Steve F. and William Oswald J. (1990) Technology of Machine Tools, McGrawHill Inc., NewYork, USA

[13] Surdia T. (2000) Pengetahuan Bahan Teknik, Pradnya Paramita, Jakarta 